12 Larkai EN, Smith JL, Lidsky MD, Graham DY. Gastroduodenal mucosa an dyspeptic symptoms in arthritic patients during chronic non-steroidal ant inflammatory drug use. Am $\mathcal{F}$ Gastroenterol 1987;82:1153-8.

13 O'Laughlin JC, Hoftiezer JW, Ivey KJ. Effect of aspirin on normal human stomach. Scand f Gastroenterol [S uppl] 1981;67:211-4

14 Hoftiezer JW, O'Laughlin JC, Ivey KJ. Effects of 24 hours of aspirin Bufferin, paracetamol and placebo on normal human gastroduodenal mucosa. Gut 1982;23:692-7.

15 Baskin WN, Ivey KJ, Krause W, Jeffrey E, Gemmell RT. Aspirin induced ultrastructural changes in human gastric mucosa. Ann Intern Med 1976;85 294-303.

16 Levy $M$. Aspirin use in patients with major upper gastrointestinal bleeding and peptic ulcer disease. $N$ Engl $f$ Med 1974;290:1158-62.

17 Rees WD, Turnberg LA. Reappraisal of the effects of aspirin on the stomach. Lancet 1980;ii:410-3.

18 Duggan JM, Dobson AJ, Johnson H, Fahey P. Peptic ulcer and non-steroidal anti-inflammatory agents. Gut 1986;27:929-33.

19 Langman MJS. Peptic ulcer complications and the use of non-aspirin non-steroidal anti-inflammatory drugs. Adverse Drug Reaction Bulletin 1986;120:448-5

20 Somerville K, Faulkner G, Langman M. Non-steroidal anti-inflammatory drugs and bleeding peptic ulcer. Lancet 1986;i:462-4.

21 Cockel R. Non-steroidal anti-inflammatory drugs-should every prescription carry a government health warning? Gut 1987;28:515-8

22 Walt R, Katschinski B, Logan R, Ashley J, Langman M. Rising frequency of ulcer perforation in elderly people in the United Kingdom. Lancet 1986; ; 489-92.

23 Coggon D, Lambert P, Langman MJS. 20 years of hospital admissions for peptic ulcer in England and Wales. Lancet 1981; ; : 1302-4.

24 Collier DStJ, Pain JA. Non-steroidal anti-inflammatory drugs and peptic ulcer perforation. Gut 1985;26:359-63.

25 Armstrong CP, Blower AL. Non-steroidal anti-inflammatory drugs and life threatening complications of peptic ulceration. Gut 1987;28:527-32.

26 Henry DA, Johnston A, Dobson A, Duggan J. Fatal peptic ulcer complications and the use of non-steroidal anti-inflammatory drugs, aspirin, and corticosteroids. $B r$ Med $\mathcal{F}$ 1987;295:1227-9.

27 Jick SS, Perera DR, Walker AM, Jick H. Non-steroidal anti-inflammator drugs and hospital admission for perforated peptic ulcer. Lancet 1987;ii:380.

28 Hawkey CJ, Prichard PJ, Somerville KW. Strategies for preventing aspirininduced gastric bleeding. Scand f Gastroenterol [Suppl] 1986;21:170-3.
29 Kimmey MB, Silverstein FE, Saunders DR, Chapman RC. Reduction of endoscopically assessed acute aspirin-induced gastric mucosal injury with cimetidine. Dig Dis Sci 1987;32:851-6.

30 Hogan DL, Thomas FJ, Isenberg JI. Cimetidine decreases aspirin-induced gastric mucosal damage in humans. Alimentary Pharmacology Therapeutic 1987;1:383-90.

31 Berkowitz JM, Adler SN, Sharp JT, Warner CW. Reduction of aspirin induced gastroduodenal mucosal damage with ranitidine. $\mathcal{F}$ Clin Gastroenterol 1986;8:377-80.

32 Berkowitz JM, Rogenes PR, Sharp JT, Warner CW. Ranitidine protects against gastroduodenal mucosal damage associated with chronic aspirin therapy. Arch Intern Med 1987;147:2137-9.

33 Fleiss JL. Statistical methods for rates and proportions. Chichester: Wiley, 1973.

34 Morris JA, Gardner MJ. Calculating confidence intervals for relative risks (odds ratios) and standardised ratios and rates. $\mathrm{Br} M$ Med $\mathcal{F}$ 1988;296:1313-6.
(a)

35 Cox DR. Analysis of binary data. London: Chapman Hall, 1970.

36 Roth SH, Bennett RE, Mitchell CS, Hartman RJ. Cimetidine therapy in nonsteroidal anti-inflammatory drug gastropathy. Arch Intern Med 1987;147: 1798-801

37 Porro GB, Pace F, Caruso I. Why are non-steroidal anti-inflammatory drugs important in peptic ulceration? Alimentary Pharmacology Therapeutic 1987;1(Suppl):540-7.

38 Eliakim R, Ophir M, Rachmilewitz D. Duodenal mucosal injury with nonsteroidal anti-inflammatory drugs. I Clin Gastroenterol 1987;9:395-9.

39 Graham DY, Smith JL, Dobbs SM. Gastric adaptation occurs with aspirin administration in man. Dig Dis Sci 1983;28:1-6.

40 Fok KH, George PJM, Vicary FR. Peptic ulcers induced by piroxicam. $B r$ Med I 1985;290:117.

41 Beermann B. Peptic ulcers induced by piroxicam. Br Med f 1985;290:789.

42 Meyer P, Thijs I. Peptic ulcers induced by piroxicam. Br Med f 1985;290:789.

43 Armstrong CP, Blower AL. Ulcerogenicity of piroxicam: an analysis of spontaneously reported data. Br Med f 1987;294:772.

44 Inman WHW, Rawson NSB. Peptic ulcer and piroxicam. Br Med $f$ 1985;290:932.

45 Husby G. The Norwegian multicenter study. Am $\mathcal{J}$ Med 1986;81(Suppl 5B): 6-10

46 Clinch D, Baneriee AK, Levy DW, Ostick G, Faragher EB. Non-steroidal anti-inflammatory drugs and peptic ulceration. $\mathcal{f} R$ Coll Physicians Lond 1987;21:183-7.

(Accepted 29 fune 1988)
Accident and Emergency

Department, Wexham Park

Hospital, Slough SL2 4HL

M S Christian, FRCS,

consultant in charge

\title{
Incidence and implications of natural deaths of road users
}

\section{S Christian}

\begin{abstract}
A prospective study was carried out over the 10 years 1978-87 to determine the incidence and implications of sudden death in road users - that is, drivers, pedestrians, cyclists, and motorcyclists. During the study period 30000 patients were seen in the same accident and emergency departments of East Berkshire after road traffic incidents or accidents, of whom 267 either were brought in dead or died within two hours after arrival. Of these patients, 64 (24\%) were found to have died of natural causes due to pre-existing disease or to have been killed in an incident that occurred as a result of a medical or psychiatric condition. Twelve of the patients sustained physical injury; all 64 came to necropsy. Only one incident resulted in the death of another person in addition to the natural death of a patient.

It is concluded that sudden natural death occurring in road users does not present an appreciable hazard to other road users.
\end{abstract}

\section{Introduction}

Any death or severe injury caused to road users by the sudden death of another road user in charge of a vehicle is usually followed by widespread publicity and expressions of public concern. Such cases are not common, but the implications of sudden natural death to a road user have been considered by several authorities and resulted in publications for the guidance of medical practitioners who may have to advise people of their fitness to drive. ${ }^{12}$ The incidence of natural deaths in road users does not appear to have been studied against a background of population density, types of roads serving the area, age groups, sex, and incidence of naturally occurring diseases.
This prospective study (1978-87) therefore had four objectives: (a) to determine the size of the problem; (b) to identify the degree of risk to other road users; (c) to determine the underlying pathological conditions leading to death; and (d) to consider whether in the light of the findings present advice to patients with certain medical conditions requires reassessment.

\section{Patients and methods}

Between 1 January 1978 and 31 December 1987 details were noted of all patients brought to the accident and emergency departments of East Berkshire who either were dead on arrival or died within two hours after arrival and in whom death was associated with a road "incident." As much history as possible was obtained from relatives, ambulance personnel, police, and witnesses. In particular, incidents involving only one vehicle were noted. Getting information about this category of patient was facilitated by the policy in East Berkshire of all patients apparently dead being brought into the resuscitation room, where death is confirmed after careful examination and certain basic investigations and examinations are performed authoritatively to confirm death. ${ }^{3}$ All such patients were subjected to a coroner's necropsy. Though in many cases there was a suspicion that a natural death had been a precipitating cause of the incident, the absence of severe external injury did not necessarily preclude traumatic death, nor did the presence of visible external injury indicate that trauma was an important factor leading to death.

Information from general practitioners was obtained when possible to ascertain the patients' previous medical history and drug treatments. In all cases full necropsy reports were obtained. 


\section{Results}

During the 10 years of the study 30000 patients who had been involved in incidents or accidents on the road were brought into the accident and emergency departments. Of the 388 who died, 267 either were brought in dead or died in the departments, usually within two hours after arrival. Of these patients, 64 $(24 \%)$ were found to have died of natural causes due to pre-existing disease or to have been killed in an incident that occurred as a result of a medical or psychiatric condition. All 64 patients on arrival in the accident and emergency department were initially categorised as victims of road traffic accidents by virtue of the circumstances and location of the incident, and all deaths were reported to the coroner and then were the subject of necropsies attended by the coroner's officer. When no traumatic cause of death was found and in those cases in which no injury had been caused to other road users coroners' inquests were usually not held.

\section{SEX AND AGE DISTRIBUTION}

The 64 victims were aged 19-89 years. Thirty six were in the 61-89 year age group and 25 in the 41-60 year age group. Fifty eight of the victims were men.

\section{CATEGORY OF ROAD USERS}

Fifty of the victims were drivers of four wheeled vehicles, of which five were heavy goods vehicles. Motorcyclists accounted for three cases, cyclists for seven, and pedestrians for four.

\section{NATURE OF INCIDENT}

Information was obtained mainly from ambulance personnel, police officers, and any passengers in the vehicles and also from any witnesses in other vehicles or people involved in any impact that may have occurred. In 16 cases car drivers had been involved in an impact with another vehicle. Car drivers whose vehicles hit another object, such as trees, walls, and road furniture, accounted for a further 16 cases. There were nine incidents in which car drivers were found in their stationary vehicles, having reached kerbs and verges of non-motorway roads. Of those incidents occurring on motorways, eight car drivers were found to have brought their vehicles to a halt either on the hard shoulder or against the barrier. Four of the heavy goods vehicles had come into contact at varying speeds with walls, buildings, or kerbs. All four pedestrians had come into contact with moving cars, and of the seven cyclists, three had been thrown off having hit a kerb, wall, or road furniture and four had been involved in an impact with a car or heavy goods vehicle. Two of the three motorcyclists had hit a wall or building. The other incident was not identified with certainty.

In this series the severity of injury was assessed by the injury severity score system. ${ }^{4}$ This system considers six separate body regions, each separate regional injury being graded 1 (minor) to 6 (maximum injury, virtually unsurvivable). The final score is derived from the sum of the squares of the three highest scores. Of the 64 patients studied, 12 had sustained serious physical injury in the incidentseven drivers, one motorcyclist, three cyclists, and one pedestrian.

\section{Drivers}

Of the drivers of the cars who sustained severe traumatic injury, two had well documented psychiatric histories. Both had left explicit written indications of their intention to use their cars as means of self destruction and both drove deliberately into hard, inanimate objects (a tree and a wall) at high speed and sustained multiple and immediately fatal injuries (injury severity score 75 in both cases). One man was a known alcoholic with a blood alcohol concentration of $65.5 \mathrm{mmol} / \mathrm{l}$ at the time of death. The remaining five drivers who died of natural causes but also sustained serious trauma in the incident had injury severity scores ranging from 9 to 25 , caused in four cases by impact with trees, walls, or buildings. The fifth driver in this category stopped his car, presumably feeling unwell, and died suddenly of gross cardiac myopathy while lighting a cigarette; a small fire was started inside the car, burning the front of his clothing and causing superficial burns to his abdomen. Interestingly, none of the drivers who died naturally at the wheel but also sustained serious physical injury was involved in impact with other vehicles or other categories of road users. The single case in which another road user was killed is described below.

A man aged 74 was driving down a narrow country road accompanied by his wife in the front seat. According to his wife, they were travelling at about $30-40$ miles an hour (48-64 kph) when the patient's hands dropped from the wheel and he slumped forward. The car proceeded in the middle of the road, slowly losing speed, and hit another car which was travelling at about 50-60 miles an hour (80-96 kph) in the opposite direction. The other driver, a man aged 32, was killed instantly. He was not wearing his seat belt and had a blood alcohol concentration of $28.2 \mathrm{mmol} / \mathrm{l}$. The death of the younger driver was due to a ruptured thoracic aorta; the death of the patient was due to a massive coronary occlusion. His only physical injury was a small graze on the forehead.

In the cases of other car drivers who suffered non-traumatic death at the wheel and whose vehicles had hit other cars, these cars were parked at the kerbside, travelling slowly, or, in one instance, stationary in a layby. In no instance were any injuries recorded to occupants of these other cars.

By far the commonest pattern was of a driver of a vehicle apparently in the last minutes of life appearing to have tried to reach a place of safety; no fewer than 38 such drivers had parked or come slowly to a halt on grass verges, kerbs, pavements, hard shoulders, or central reservations of motorways, sometimes impacting with trees, walls, and various items of road furniture. From ambulance and police reports evidently some of the cars were found with their engines still running but in neutral gear, suggesting a few seconds of warning to the victim of some impending catastrophe. It was also reported that in a few cases in which the car had finally hit a wall or tree the victim's foot was still resting on the accelerator pedal with the car in gear.

\section{Pedestrians, motorcyclists, and cyclists}

Of the deaths in pedestrians, three occurred when the pedestrians almost literally dropped dead in front of cars travelling at various speeds but escaped serious physical injury. One of these non-traumatic deaths was occasioned by sudden rupture of an abdominal aortic aneurysm and two were due to a ruptured myocardial infarct. The fourth death in a pedestrian occurred in a 48 year old woman with a long history of psychiatric problems who was seen deliberately to throw herself on to the motorway in the path of fast moving traffic.

The motorcyclist who sustained severe physical injuries (ruptured aorta) was a known epileptic who because of the frequency and severity of his attacks had been told not to ride his motorbike. His severe epileptic fit while riding his machine at high speed resulted in his fatal collision with a building. The three cyclists who died of natural causes but also sustained injuries as a result of impact with another vehicle had injury severity scores of 9 or less.

\section{AETIOLOGY OF DEATH}

By far the largest group of patients in this study 
suffered sudden death as a result of cardiovascular disease. Fifty six came into this category, only one of whom was a diabetic, and there was no reason to believe that this patient's diabetes was directly related to his terminal event. No fewer than 43 of the 56 patients had coronary occlusion, of whom 14 showed gross triple coronary artery disease at necropsy.

All three patients who used the highway for their final self destructive act had a history of psychiatric problems. In two cases a clear indication in writing that their death was planned was available and clearly related to the psychiatric disorder.

No fewer than seven deaths in this series were due to rupture of an abdominal aortic aneurysm. Of these, six were in car drivers and three occurred on motorways: in all the car drivers, however, there was ample evidence that in their last moments of life they attempted to steer on to the hard shoulder or verge or, in one instance, the central reservation of a motorway. In none of these instances was there any evidence of injury to other road users, though one incident caused considerable damage to two or three other vehicles.

\section{PREVIOUS MEDICAL HISTORIES}

In 50 of the 56 cases of sudden death due to cardiovascular disease inquiries were made about the patients' pre-existing illnesses and whether they were receiving treatment, and also whether their doctors and relatives knew of their condition. From the information available in 25 cases neither the patients nor their relatives were aware of any medical problem. This group included all seven patients who died suddenly of a ruptured abdominal aortic aneurysm, none of whom had consulted their doctors for the condition. Twenty one patients were receiving or had received treatment for their cardiovascular disease before death. No information was obtained in four cases.

There was no case of any dead driver in the group having been advised not to drive because of the underlying medical condition; in the whole series only the epileptic patient had been told specifically not to drive his motorbike. Detailed information on fitness to drive in the three patients with psychiatric problems was not available.

\section{Discussion}

During the past three decades several investigations have aimed at assessing the risk to road users of sudden illness or even death in another road user. In 1956 the World Health Organisation produced a document which attempted to define a standard of fitness desirable in drivers. ${ }^{1}$ The study was based almost entirely on suppositions rather than clinical studies, but publication of the report certainly gave clear indication that there might be cause for concern. Results of subsequent studies were conflicting. Waller suggested that drivers with cardiovascular disease had twice as many accidents as a control group, ${ }^{5}$ whereas Ysander found that the same group of patients had only half the number of accidents as the controls. ${ }^{6}$

Grattan and Jeffcoate in a review of published work and a personal study totalling nearly 10000 accidents resulting in injury or death looked specifically for acute illness in road users at the time of accident. ${ }^{7}$ In only 15 instances had the acute illness caused or almost certainly caused the accident, representing an incidence of 1.5 episodes of acute illness/1000 accidents resulting in injury or death. That figure was closely similar to the incidence in this study, which found $2 \cdot 1$ instances (including the three suicides and death of the epileptic)/1000 such accidents.

Baker and Spitz reported a prospective study in which 226 road traffic incidents were traced to the spontaneous death of the driver. ${ }^{8}$ There was only one fatality to other road users. They pointed out that myocardial infarction was the commonest cause of sudden death and questioned whether people with heart disease should be denied the right to drive. They concluded that spontaneous deaths in drivers were not a substantial threat to other road users, nor were they particularly common.

The Road Traffic Act 1974, which came into force in Britain in January 1976, clearly defined certain medical conditions, and in particular epilepsy, and the conditions under which a licence may or may not be granted to applicants with a history of epilepsy. The act granted the provision of lifetime licences (that is, up to age 70) and imposed a statutory duty on licence holders to notify the licensing authorities of any disability that would be considered potentially important in regard to their fitness to drive. ${ }^{9}$

This study is made against the backgrounds of the Road Traffic Act 1974, the increasing age of the population, and the larger number of vehicles on our roads than at any time in the past. Because of these changing factors no previous surveys in the United Kingdom can be used as controls. Nevertheless, the occurrence of sudden death in road users appears to represent an extremely small risk to other road users. In this series one fatality to another road user in 64 incidents over 10 years in a catchment area of 360000 does not appear to represent a serious problem. Any form of screening to exclude high risk patients from driving-for example, those with evidence of myocardial ischaemia, coronary artery disease, smokers, hypertensives, and diabetics-would bar unacceptably high numbers of people over 50 , the financial implications of which would be quite unacceptable in view of the poor returns that could be expected.

There were three suicides in road users, and these deaths have been the cause of concern in the past. Jenkins and Sainsbury suggested that deaths to drivers in which only one vehicle was involved may be disguised suicides. ${ }^{10}$ In this series the age distribution and seasonal variation of these incidents did not coincide with the usual picture for known suicides from other methods, and though deaths to drivers involving single vehicles included undoubted cases of a deliberate self destructive act, they were not an important factor in altering the statistics for suicides in the population as a whole. The occurrence of the three suicides in this series should be viewed against the background of a 10 year study period.

An important finding was the number of patients who died suddenly of ruptured abdominal aortic aneurysms. All seven cases occurred in men, in three while they were driving on a motorway, and in none was there any pre-existing knowledge of the condition. Abdominal aortic aneurysms, in particular those producing acute symptoms, are becoming increasingly common in our emergency rooms. " Indeed, abdominal aortic aneurysms requiring immediate surgery outnumber perforated peptic ulcers. ${ }^{12}$ This pattern is likely to continue, especially in view of the increasing longevity of the population. I therefore suggest that palpatation or ultrasonography of the abdomen should be included as a routine measure in any patient in the relevant age group attending for a medical consultation, particularly men. Probably any form of self examination should also be encouraged. By these means abdominal aneurysms might be detected before they enter the acute phase.

The Medical Commission on Accident Prevention's Medical Aspects of Fitness to Drive did not consider aneurysms to be a serious risk. ${ }^{2}$ It states: "The presence of aortic aneurysms, whether successfully 
repaired or not, does not preclude patients from holding an ordinary driving licence." Possibly this statement should be extended to include suggestions relating to screening of patients of the relevant age group and sex to identify such high risk disease.

\section{Conclusions}

In this study there was no evidence to suggest that sudden natural death in road users, mainly from cardiovascular disease, represents a substantial threat to other road users. It is reasonable to presume that the number of road users will continue to increase, including the number of elderly road users in all categories. As yet there is no evidence of any appreciable drop in the $50 \%$ mortality from coronary heart disease, and there certainly appears to be no justification for restricting or depriving that group of patients of driving licences because of their pre-existing cardiac condition. The group represented by the men who collapsed and died suddenly on the road from ruptured undiagnosed abdominal aortic aneurysms should be a cause for concern. It would be economically unacceptable and inappropriate to institute routine medical examinations for all drivers over a certain age to rule out the possibility of cardiac conditions that are still responsible for the vast majority of natural deaths on the road. In relation to these conditions the recommendations in the handbook dealing with medical fitness to drive ${ }^{2}$ appear to be valid, appropriate, and sensible.

1 World Health Organisation. Accident prevention. 2nd rev. Geneva: WHO, 1956.

2 Medical Commission on Accident Prevention. Medical aspects of fitness to drive. A guide for medical practitioners. London: MCAP, 1985.

3 Christian MS, Gosnold JK, Kersley PN. Confirmation of death. Br Med J 1980;281:717-8.

4 American Association for Automotive Medicine. The abbreviated injury scale. Chicago, Ill: AAAM, 1985 .

5 Waller JA. Chronic medical conditions and traffic safety. $N$ Engl $f$ Med 1965;273:1413-20.

6 Ysander L. The safety of drivers with chronic diseases. $\mathrm{Br} \mathcal{F}$ Ind Med 1966;23:28-36.

7 Grattan E, Jeffcoate GO. Medical factors and road accidents. $\mathrm{Br}$ Med $\mathcal{J}$ 1968; : $: 75$.

8 Baker S, Spitz WU. An evaluation of the hazard created by a natural death at the wheel. N Engl f Med 1970;283:405-9.

9 Road Traffic Act 1974. London: HMSO, 1974.

10 Jenkins J, Sainsbury P. Single-car road deaths-disguised suicides? Br Med $\mathcal{f}$ 1980;281:1041.

11 Collins J. Screening for abdominal aortic aneurysms. Br $\mathcal{F}$ Surg 1985;72:851-2.

12 Gowlands-Hopkins MF. Abdominal aortic aneurysms. Br Med $\mathcal{F}$ 1987;294 $790-1$
Cobbold Laboratories, University College and Middlesex School of Medicine, London WIN 8AA

R Homburg, MB, research fellow

N A Armar, MRCOG, research fellow

A Eshel, MD, research fellow J Adams, DMU, senior ultrasonographer H S Jacobs, FRCP, professor of reproductive endocrinology

Correspondence to: Professor H Jacobs.

\title{
Influence of serum luteinising hormone concentrations on ovulation, conception, and early pregnancy loss in polycystic ovary syndrome
}

\author{
R Homburg, N A Armar, A Eshel, J Adams, H S Jacobs
}

\begin{abstract}
Women with the polycystic ovary syndrome do not respond well to treatment with luteinising hormone releasing hormone. To determine whether this might be due to an underlying endocrine disturbance basal concentrations of luteinising hormone were measured in 54 infertile women treated with pulsatile luteinising hormone releasing hormone and concentrations at the time of maximum follicular growth were measured in 23 of the patients. Forty one patients ovulated.
\end{abstract}

Forty one patients ovulated and 27 conceived, but nine pregnancies terminated within four weeks after ovulation. Basal luteinising hormone concentrations were significantly lower in those who conceived $(12.4$ (range 1-3-29.0) IU/l) than in those who did not (19.0 $(3.5-50.0) \mathrm{IU} / \mathrm{I})$ and in those whose pregnancy progressed $(9.6(1 \cdot 3-29.0)$ IU/1) than in those with early loss of pregnancy $(17.9(7 \cdot 0-29 \cdot 0)$ IU/1). Concentrations at the time of maximum follicular growth were significantly lower in women who ovulated $(9.4$ (2.9$35.4)$ IU/1) than in those who did not $(29.0(7 \cdot 0-50.0)$ IU/I) and in those who conceived (6.2 (2.9-8.5) IU/I) than in those who did not $(17.9(4 \cdot 0-50 \cdot 0)$ IU/I).

These results indicate that high concentrations of luteinising hormone during the follicular phase in women with polycystic ovaries have a deleterious effect on rates of conception and may be a causal factor in early pregnancy loss.

\section{Introduction}

Infertile women with polycystic ovaries who do not ovulate and are resistant to clomiphene do not respond well to treatment with luteinising hormone releasing hormone in terms of rates of ovulation and conception; moreover, these patients often suffer early loss of pregnancy. ${ }^{\prime}$ This disappointing outcome is in direct contrast to the excellent results obtained with the same treatment in patients with hypogonadotrophic hypogonadism.

Patients with the polycystic ovary syndrome often have raised basal concentrations of luteinising hormone ${ }^{2}$ and we have shown that, when ovulation is induced with pulsatile luteinising hormone releasing hormone, luteinising hormone concentrations often remain high throughout the follicular phase. ${ }^{3}$ In this study we measured luteinising hormone concentrations in patients with the polycystic ovary syndrome being treated with pulsatile luteinising hormone releasing hormone and related them to whether or not ovulation and conception occurred and to the fate of the pregnancy. We have reported the clinical results in 48 of the patients elsewhere. ${ }^{4}$

\section{Patients and methods}

In 54 patients who were infertile and had failed to ovulate in response to multiple courses of clomiphene citrate polycystic ovaries were detected by ultrasonography, using the criteria of Adams et al. ${ }^{\mathrm{s}}$ Eight of the women had amenorrhoea and 46 had oligomenorrhoea.

All patients were treated with pulsatile injections of $15 \mu \mathrm{g}$ luteinising hormone releasing hormone (Fertiral, Hoechst) given subcutaneously at intervals of 90 minutes with a miniaturised infusion pump. Twelve women failed to ovulate so were given luteinising hormone releasing hormone intravenously at the same dose and frequency. Ovulation was detected by ultrasonography and was confirmed by the appearance of a corpus luteum together with a serum progesterone concentration $\geqslant 25 \mathrm{nmol} / 1$ during the mid-luteal phase. Pregnancy was diagnosed when human chorionic gonadotrophin was detected in serum and a gestational sac was detected on ultrasonography. Early loss of 